Article

\title{
Vigna subterranea (L.) Verdc Starch-Soluble Dietary Fibre Potential Nanocomposite: Thermal Behaviour, Morphology and Crystallinity
}

\author{
Yvonne Maphosa ${ }^{1}$, Victoria Adaora Jideani ${ }^{1, *(D)}$ and Daniel Imwansi Ikhu-Omoregbe ${ }^{2}$
}

Citation: Maphosa, Y.; Jideani, V.A.; Ikhu-Omoregbe, D.I. Vigna

subterranea (L.) Verdc Starch-Soluble Dietary Fibre Potential

Nanocomposite: Thermal Behaviour, Morphology and Crystallinity.

Processes 2022, 10, 299. https:/ / doi.org/10.3390/pr10020299

Academic Editor: Yue Li

Received: 25 November 2021

Accepted: 23 January 2022

Published: 2 February 2022

Publisher's Note: MDPI stays neutral with regard to jurisdictional claims in published maps and institutional affiliations.

Copyright: (C) 2022 by the authors. Licensee MDPI, Basel, Switzerland. This article is an open access article distributed under the terms and conditions of the Creative Commons Attribution (CC BY) license (https:// creativecommons.org/licenses/by/ $4.0 /)$
1 Department of Food Science and Technology, Cape Peninsula University of Technology, P.O. Box 1906, Bellville, Cape Town 7535, South Africa; yvonnemaphosa@gmail.com

2 Department of Chemical Engineering, Cape Peninsula University of Technology, P.O. Box 1906, Bellville, Cape Town 7535, South Africa; ikhuomoregbed@cput.ac.za

* Correspondence: jideaniv@cput.ac.za; Tel.: +27-788391615
Abstract: Bambara groundnut (BGN) starch-soluble dietary fibre nanocomposite (STASOL) was manufactured by grafting $1.95 \mathrm{~g}$ BGN soluble dietary fibre (BGN-SDF) onto $15 \mathrm{~g}$ BGN starch (BGNS). The particle sizes, functional groups, crystallinity, morphology and thermal properties of BGNS, BGN-SDF and STASOL were studied using a Zetasizer, Fourier transform infrared, X-ray diffraction, scanning electron microscope and differential scanning calorimetry, respectively. STASOL had a particle size and conductivity of $74.01 \mathrm{~nm}$ and $-57.3 \mathrm{mV}$, respectively. BGN-SDF and STASOL were amorphous and BGNS was classified as type $C$ starch, typical of legumes. The biopolymers had functional groups in the regions 2900-3600, 1600-1642, 900-1200 and 800-1300 cm ${ }^{-1}$, which could be attributed to the vibrational stretching of $\mathrm{OH}$ groups, vibration of $\mathrm{OH}$ groups in the non-crystalline region of starch, vibration of $\mathrm{C}-\mathrm{O}, \mathrm{C}-\mathrm{C}$ and $\mathrm{C}-\mathrm{H}-\mathrm{O}$ bonds and the vibration of $\mathrm{C}-\mathrm{O}$ and $\mathrm{C}-\mathrm{C}$ bonds, respectively. BGNS had smooth, oval structures while BGN-SDF and STASOL exhibited irregular, polygonal morphologies. STASOL was the most thermally stable biopolymer, disintegrating at $293{ }^{\circ} \mathrm{C}$, therefore suggesting that it would find use in high-temperature food applications such as baking.

Keywords: Bambara groundnut; starch; soluble dietary fibre; nanocomposites; phase behaviour

\section{Introduction}

Bambara groundnut (BGN) (Vigna subterranea (L). Verdc) is an underutilised legume commonly grown by low-income farmers in sub-Saharan Africa [1,2]. It is the third most important legume, after Arachis hypogaea (groundnuts) and Vigna unguiculata (cowpea), in terms of consumption and socioeconomic status [3]. It is high in soluble dietary fibre (SDF) (17-24\%, dry mass) and starch (22-50\%, dry mass) [4], making it a good source of both polysaccharides. The starch content of BGN is comparable to that of the commonly used potato (15-23\%) and maize (24-25\%) [5] starch sources. The increasing demand for starch by the food industry due to decreased cereal production as a result of climate change [6] makes BGN starch (BGNS) a potential alternative. The use of starch from locally produced, underutilised crops such as BGN not only alleviates the pressure to overutilise cereal and tuber starches, but also reduces the costs associated with importation of common starches from outside Africa [7].

The industrial utilisation of native starch is limited because of its inherent undesirable attributes such as instability to various processing conditions [8,9]. These attributes include its tendency to retrograde and undergo syneresis, as well as instability to various temperatures, shear and $\mathrm{pH}[8,10]$. Several chemical methods have been applied in the modification of BGN starches. These include acetylation, carboxymethylation and oxidation [7]. The choice of modification method is dependent on several factors such as end-use, desired functional properties, toxicity levels as well as permitted chemical residues in the final 
modified starch. Another way of mitigating these limiting properties involves modification by complexing starch with a more robust biopolymer such as SDF. Bambara groundnut SDF are prebiotic [11], have high oil binding capacities and are rich in bioactive compounds, namely, uronic acids and polyphenols, with crucial physiological and functional benefits [12]. Both BGN-SDF and BGNS currently have no reported uses in the food industry. Furthermore, there is limited knowledge on the synthesis of nanocomposite food polymers, and nothing is known about BGNS-SDF nanocomposite (STASOL).

Composites are functionalised molecules that possess the characteristics of both the grafted molecules and the natural polymer [13]. Complexes that have been studied include starch-dietary fibre conjugates [14], starch-lipid composites [15], starch-wheat bran composites [16], protein-dietary fibre complexes and starch-pectin blends [14]. Gulu [7] produced a BGNS-catechin complex using the free radical-induced grafting method. The free radicalinduced grafting method is commonly coupled with a self-assembling method in mediums such as ethanol [15]. This method employs an ascorbic acid-hydrogen peroxide redox pair as an initiator system [16]. Hydrogen peroxide oxidises ascorbic acid-forming hydroxyl and ascorbate radical intermediates [17]. When added to polysaccharides such as starch, the ascorbic acid-hydrogen peroxide combination catalyses the activation of the polysaccharide chains towards radical reaction. The initiator system produces hydroxyl radicals that abstract hydrogen atoms from the polysaccharide's OH- groups, leaving the polysaccharide chain exposed thus allowing it to form self-aggregates with other compounds by forming intra- and inter-molecular associations [7].

In this study, the free radical-induced grafting method was used to complex BGNS and BGN-SDF to synthesise STASOL. The particle size, conductivity, functional groups, crystallinity, morphology and thermal properties of STASOL were characterised.

\section{Materials and Methods}

\subsection{Source of Materials}

Bambara groundnut (BGN) seeds were purchased from Triotrade, Johannesburg, South Africa. The seeds were manually sorted and only the black-eye variety was used. Analytical grade chemicals were used in this study (Sigma-Aldrich).

\subsection{Extraction of BGN Soluble Dietary Fibre and Starch}

The method of Maphosa and Jideani [12] was followed in the extraction of BGN-SDF and BGNS. Whole seeds were washed, dried at $50{ }^{\circ} \mathrm{C}$ for $48 \mathrm{~h}$ (Cabinet drier, Model: 1069616; Geiger Klotzbucher, Cape Town, South Africa) and milled using a hammer mill (Trapp TRF 40, Animal ration shredder Brazil) with a sieve size of $250 \mu \mathrm{m}$. Flour (200 g) and distilled water $(500 \mathrm{~mL})$ were blended (Cuisine systeme 5200 XL automatic, Magimix ${ }^{\circledR}$, Paris, France) for $3 \mathrm{~min}$ and the slurry was centrifuged $\left(15 \mathrm{~min}, 25^{\circ} \mathrm{C}, 1500 \times g\right)$ (Avanti ${ }^{\circledR} \mathrm{J}$-E Centrifuge, JSE111330, Beckman Coulter Inc., Brea, CA, USA). The supernatant and residue were used for the isolation of BGN-SDF and BGNS, respectively. From the supernatant, proteins were precipitated by adjusting the $\mathrm{pH}$ of the soluble fraction from $\mathrm{pH} 3$ to $\mathrm{pH} 9$ using $1 \mathrm{M} \mathrm{NaOH}$ and $1 \mathrm{M} \mathrm{HCl}$. Following precipitation, the soluble fraction was centrifuged $\left(10 \mathrm{~min}, 25^{\circ} \mathrm{C}\right.$, $1500 \times g)$. The supernatant was filtered against four diafiltration volumes of Millipore water [12] and subjected to a tangential flow filtration system (Spectrum Laboratories Inc., Rancho Dominguez, CA, USA) and the recovered BGN-SDF fraction was freeze-dried. The residue was wet screened in $2 \mathrm{~L}$ of water through a $53 \mu \mathrm{m}$ sieve (Endecotts Limited, London, UK) and the washings that passed through the sieve were centrifuged (10 min, $\left.25^{\circ} \mathrm{C}, 1500 \times g\right)$. The pellet was air-dried as starch. The yield of BGNS and BGN-SDF was calculated as the weight of polysaccharide divided by $100 \mathrm{~g}$ flour, expressed as a percentage.

\subsection{Phase Behaviour Study of BGNS and BGN-SDF}

The phase behaviour of different concentrations of BGNS:BGN-SDF was studied. The concentrations of BGNS:BGN-SDF (5:1.95, 15:0.65, 15:1.95, 10:1.3, 5:0.65) studied were determined using an augmented $2^{2}$ factorial design. Samples were weighed into centrifuge 
tubes then mixed with $0.1 \mathrm{M} \mathrm{NaCl}$ and $10 \mathrm{mM}$ Tris- $\mathrm{HCl}$ buffer at $\mathrm{pH}$ 7.2. The mixture was vortexed at high speed for $1 \mathrm{~min}$ and left to stand overnight at $20^{\circ} \mathrm{C}$. Visual detection of samples was carried out and pictorial representations were obtained. Phase separation was also determined using the Turbiscan (Turbiscan MA 2000, Formulaction, Toulouse, France) following the method of Adeyi et al. [18]. Each sample $(7 \mathrm{~mL})$ was placed in a $65 \mathrm{~mm}$ long Turbiscan tube and scanned along the height of the tube at $10 \mathrm{~min}$ intervals for $1 \mathrm{~h}$. Multiple scans were carried out and from those, phase separation of the biopolymers was observed. Each scan provided a curve, and all curves were laid on a single graph. From these scans, stability or separation was observed. The curves generated during the measurements were used to provide the backscattering (BS) and transmission flux percentage relative to the instrument's internal standard as a function of the height of the sample. The most stable formulation was selected for the production of STASOL.

\subsection{Production of Starch-Soluble Dietary Fibre Nanocomposite}

A modified method of Gulu [7] was adopted in the preparation of STASOL from BGNS and BGN-SDF using concentrations selected from the phase behaviour studies in Section 2.3 (BGNS = $15 \mathrm{~g}$, BGN-SDF = $1.95 \mathrm{~g}$ ). The concentrations of water and chemicals for chemically modifying BGNS used were determined by Gulu [7] as $37.5 \mathrm{~mL}$ deionised water, $16.5 \% \mathrm{H}_{2} \mathrm{O}_{2}(120 \mathrm{v})$ and $0.1 \%$ of ascorbic acid, using an augmented $2^{2}$ factorial experiment. In a $100 \mathrm{~mL}$ Schott bottle, BGNS, deionised water, $\mathrm{H}_{2} \mathrm{O}_{2}$ and ascorbic acid were mixed then incubated at $90{ }^{\circ} \mathrm{C}$ for $45 \mathrm{~min}$ in a temperature-controlled water bath (Ecobath, LaboTec). The mixture was cooled to room temperature before precipitating with $40 \mathrm{~mL}$ absolute ethanol drop wise with continuous agitation in a sonicator (Sonicator Heat Systems-Ultrasonics, Inc., Model W-225R, Krugersdorp, South Africa) for $10 \mathrm{~min}$ at high speed. The mixture was then centrifuged (Jouan MR1812 Thermo Electron Corporation) at $6000 \mathrm{rpm}$ for $5 \mathrm{~min}$ and the supernatant was discarded. To obtain regenerated BGNS particles as well as remove $\mathrm{H}_{2} \mathrm{O}_{2}$ and ascorbic acid, the residue was rinsed three times with $40 \mathrm{~mL}$ absolute ethanol. BGNS (15 g) and BGN-SDF (1.95 g) were dissolved in 40 and $15 \mathrm{~mL}$ ethanol:water $(1: 1 \mathrm{v} / \mathrm{v})$, respectively. The two solutions were mixed to obtain a molecular dispersion of BGNS and BGN-SDF and left to react for $24 \mathrm{~h}$, on a magnetic stirrer (Dragon Lab, MS-H-Pro), in a dark place. The resulting solution was freeze-dried (VirTis Genesis 25EL).

\subsection{Chemical Analysis of BGNS, BGN-SDF and STASOL}

The yields of BGNS and BGN-SDF were calculated based on $100 \mathrm{~g}$ BGN flour. The chemical composition of BGNS, BGN-SDF and STASOL was determined by analysing their protein (Leco, TruSpec ${ }^{\circledR} \mathrm{N}$ ), fat (Gas Chromatography) and ash (muffle furnace) content according to AOAC procedures.

\subsection{Conductivity and Particle Size Determination of BGNS, BGN-SDF and STASOL}

Conductivity and particle sizes of the biopolymers were analysed using a Zetasizer (Nano ZS90, Malvern Nanoseries Instruments) at a temperature of $25^{\circ} \mathrm{C}$ and viscosity of $10 \mathrm{cP}$. Samples $(0.2 \mathrm{~g})$ were suspended in $5 \mathrm{~mL}$ methanol and a polystrene zeta potential cell (zen1020, Malvern Instruments) was used in the analysis of particle size. A dip cell (zen1002, Malvern Instruments) with a pair of parallel Pd electrodes was used to provide electrical trigger on charged particles. All samples were run 11 times with each run lasting 10 s. Data were analysed using the Zetasizer Software.

\subsection{Functional Groups of BGNS, BGN-SDF and STASOL}

Fourier transform infrared (FTIR) spectra were carried out on a Golden-gate diamond single reflectance ATR in an FTS 7000 FT-IR spectrometer with a DGTS detector (DIGILAB, Randolp, MA, USA) [19]. Finely powdered samples were mixed with dry KBr (1:100, sample: $\mathrm{KBr}$ ) in a vibratory ball mill capsule for $5 \mathrm{~min}$. The mixture was transferred to a specadie producing an $8.5 \mathrm{~mm}$ diameter film which was analysed in the beam of the 
FTIR spectrophotometer. The spectra were recorded at absorbance mode, at a resolution of $4 \mathrm{~cm}^{-1}$ with 128 co-added scans.

\subsection{Crystallinity of BGNS, BGN-SDF and STASOL}

Powder X-ray diffraction (XRD) was used to determine the structures of BGNS, BGNSDF and STASOL. Powder XRD patterns were collected in transmission using an X-ray diffractometer (Phillips PW 3830/40 Generator) following the method of Afolabi [20]. All samples were measured in the $2 \theta$ angle range between $5^{\circ}$ and $70^{\circ}$ at a step size of 0.034 , target voltage of $40 \mathrm{kV}$, target current of $100 \mathrm{~mA}$, the ageing time of $5 \mathrm{~min}$ and radiation wavelength of $0.1542 \mathrm{~nm}$.

\subsection{Morphology and Microstructure of BGNS, BGN-SDF and STASOL}

To study the morphology and microstructure of the biopolymers, a scanning electron microscope (SEM, Leo $\left.{ }^{(\mathrm{R})} 1430 \mathrm{VP}\right)$ was used. A freeze-dried thin layer of the sample was mounted on aluminium stubs with double-sided carbon tape then coated with a thin layer of gold to make it electrically conducting. Two fields per sample were studied to obtain a representative number of particles $(\mathrm{n}=300-800$ particles). The samples were examined at $7 \mathrm{kV}[21]$.

\subsection{Fluorescence Analysis of BGNS, BGN-SDF and STASOL}

A $10 \mathrm{mg}$ sample was dissolved in $50 \mathrm{~mL}$ deionised water then transferred to a cuvette $(1 \mathrm{~cm}$ path length) and the fluorescence was measured using a spectrofluorometer (Perkin Elmer, LS 55, Fluorescence Spectrometer, Llantrisant, UK) following the method of Singh et al. (2010). The settings used were: excitation and emission slit $(2.5 \mathrm{~nm})$; acquisition interval $(1 \mathrm{~nm})$; integration time for the total luminescence spectra $(0.1 \mathrm{~s})$; integration time for the synchronous scan method $(0.05 \mathrm{~s})$. The excitation emission matrices spectra were recorded from 250 to $500 \mathrm{~nm}$ at $5 \mathrm{~nm}$ intervals, while the emission spectra ranged between 280 to $600 \mathrm{~nm}$ at $5 \mathrm{~nm}$ intervals. Excitation and emission monochromator in the range of 250-500 nm were run concurrently to obtain a synchronous fluorescence spectrum.

\subsection{Thermal Analysis of BGNS, BGN-SDF and STASOL}

The thermal analysis of STASOL was carried out using differential scanning calorimetry (DSC) (Perkin Elmer, DSC 6000, UK) and thermogravimetric analysis (TGA) (Perkin Elmer, TGA 4000, UK) according to a modified method of Liu et al. [14] and Maphosa and Jideani [12]. Samples (2 mg) were placed in DSC pans and empty pans were used as references. A linear heating rate of $10^{\circ} \mathrm{C} / \mathrm{min}$ from 25 to $400{ }^{\circ} \mathrm{C}$ with nitrogen at a flow rate of $20 \mathrm{~mL} / \mathrm{min}$ was used. The temperature difference across the sample and the reference chromel wafers gave a measurement of heat flow. A pure indium standard was used for calibration and the experiments were conducted in triplicate. The thermal behaviour of samples was observed as peaks. The extrapolated peak (Tp), peak area and enthalpy of gelatinisation $(\Delta \mathrm{H})$ were recorded.

Thermogravimetric analysis was conducted at a linear heating rate from 25 to $700{ }^{\circ} \mathrm{C}$ at a heating rate of $20^{\circ} \mathrm{C} / \mathrm{min}$ under nitrogen at a flow rate of $20 \mathrm{~mL} / \mathrm{min}$. A $7 \mathrm{mg}$ sample was used, and mass loss was represented in a graph.

\subsection{Data Analysis}

All experiments were carried out in triplicate. Data were expressed as mean \pm standard deviation. For statistical analysis, IBM Statistical Package for the Social Sciences (SPSS) was used. The results were subjected to multivariate analysis of variance (MANOVA) to establish differences between treatments. Duncan's multiple range test was used to separate means where a significant $(p \leq 0.05)$ difference existed. 


\section{Results and Discussion}

\subsection{Phase Behaviour of Bambara Groundnut Starch and Soluble Dietary Fibre Concentrations} in Solution

Five combinations of BGNS and BGN-SDF were successfully studied, and the visual observations and initial backscattering (BS) determined using the Turbiscan are given in Table 1. From the visual observation, the combinations made up of 15:1.95 and 15:0.65 (BGNS:BGN-SDF) did not exhibit any separation while those made up of 10:1.3 and 5:0.65 (BGNS:BGN-SDF) showed clear separation of phases. This suggested that high amounts of BGNS produced more stable mixtures.

Table 1. Visual representation of phase separation between BGNS and BGN-SDF.

\begin{tabular}{|c|c|c|c|}
\hline BGNS:BGN-SDF & Visual Observation & Initial BS (\%) & Pictorial Representation \\
\hline $5: 0.65$ & $\begin{array}{c}\text { Visible separation of polymer phases } \\
\text { Syneresis }\end{array}$ & 78.4 & \\
\hline 10:1.3 & $\begin{array}{c}\text { A thin layer of SDF observed on the top } \\
\text { No syneresis observed } \\
\text { Two layers of polymers observed }\end{array}$ & 79.8 & \\
\hline $15: 1.95$ & No separation observed & 82.9 & \\
\hline $15: 0.65$ & No separation observed & 77.1 & \\
\hline 5:1.95 & $\begin{array}{c}\text { A thin layer of SDF observed on the top } \\
\text { No syneresis observed } \\
\text { Two layers of polymers observed }\end{array}$ & 80.9 & \\
\hline
\end{tabular}

The least (initial BS $=77.1 \%$ ) and most (initial BS $=86.9 \%$ ) stable combinations were 15:0.65 and 15:1.95 (BGNS:BGN-SDF), respectively. The initial BS flux percentage ranged from 78.4\% (5 g BGNS:0.65 g BGN-SDF) to 82.9\% (15 g BGNS:1.95 g BGN-SDF). Stability was also observed as the extent of separation between the Turbiscan BS scans. The Turbiscan profiles of the different BGNS and BGN-SDF combinations are detailed in Figure 1. The $x$-axis denotes the height of the tube, and the y-axis denotes the backscattering flux percentage [22]. The Turbiscan profiles of all combinations followed the same path as the initial scan. However, with the increase in time, a decrease in BS flux percentage was 
observed, resulting in scans that were not perfectly overlaid. The most stable combination exhibited the least separated BS scans.
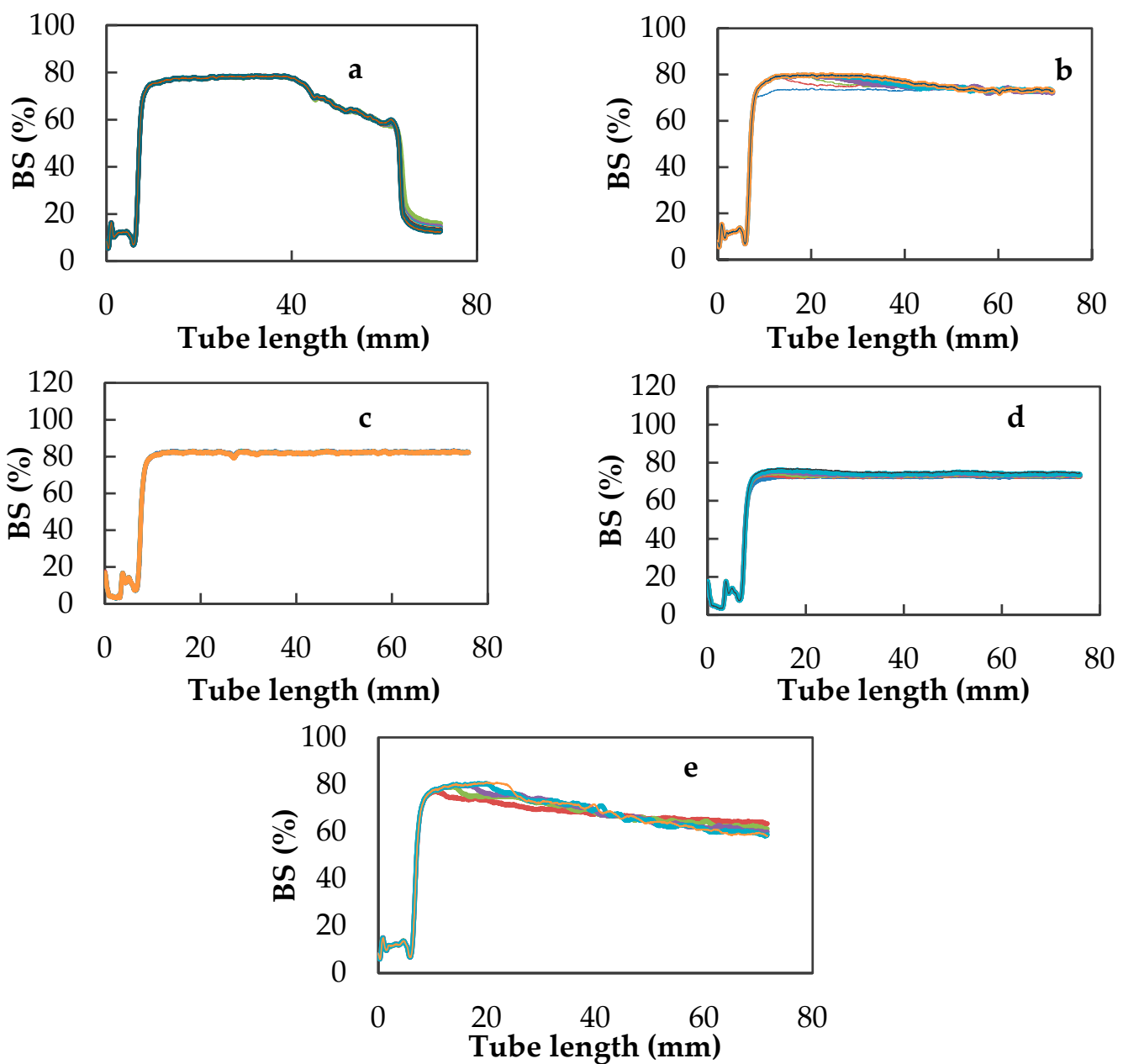

Figure 1. Changes in the backscattering (BS) profile (\%) as a function of sample height with varying BGNS:BGN-SDF concentrations at (a) 5:0.65, (b) 10:1.3, (c) 15:1.95, (d) 15:0.65, and (e) 5:1.95.

The phenomenon responsible for instability and separation of BGNS and BGN-SDF fractions was proposed to be segregative phase separation. This form of separation occurs between biopolymers with a similar charge, two neutral biopolymers or between a neutral biopolymer and a charged biopolymer [16]. At low concentrations, segregative phase separation leads to electrostatic repulsion or steric exclusion, resulting in the biopolymers separating into two phases [23,24].

Different polysaccharides are incompatible when there is no attraction between them, that is, if the entropy difference exceeds the enthalpy of mixing [25]. The complexing of macromolecules is accompanied by a low entropy change, hence, the weak inter-molecular interactions become sufficient to stabilise the complex. Such interactions are typical of unfolded chains able to form inter-chain contacts [25]. As biopolymer concentration increases, the interaction between unfolded biopolymer chains also increases, thus increasing the stability of the biopolymer-biopolymer complex [23].

3.2. Yield and Chemical Composition of Bambara Groundnut Soluble Dietary Fibre and Bambara Groundnut Starch-Fibre Nanocomposite

Figure 2 shows visual representations of the extracted BGNS, BGN-SDF and STASOL. 


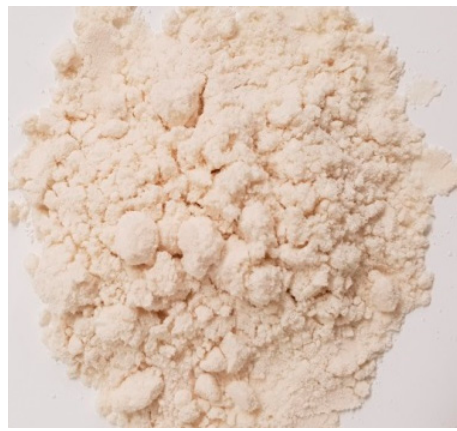

BGNS

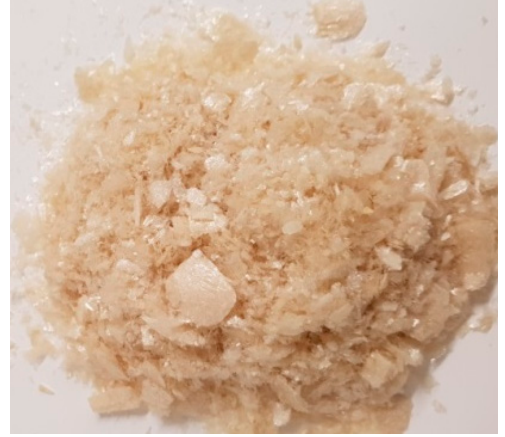

BGN-SDF

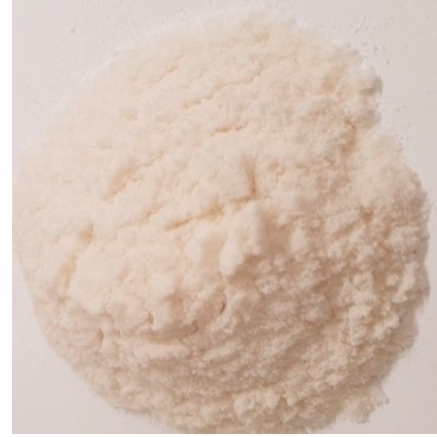

STASOL

Figure 2. Pictorial representation of BGNS, BGN-SDF and STASOL. BGNS = Bambara groundnut starch; BGN-SDF = Bambara groundnut soluble dietary fibre; STASOL = Bambara groundnut starchfibre nanocomposite.

The yield of BGNS was 35\% and the starch obtained was an odourless white powder. BGNS was highly pure with a low amount of protein $(1.74 \%)$, low fat $(0.56 \%)$ and low ash $(0.07 \%)$ (Table 2$)$.

Table 2. Chemical composition of BGNS, BGN-SDF and STASOL.

\begin{tabular}{cccccc}
\hline & Moisture (\%) & Ash (\%) & Protein (\%) & Fat (\%) & Carbohydrates (\%) \\
\hline BGNS & $10.84 \pm 0.0436^{\mathrm{a}}$ & $0.07 \pm 0.0100^{\mathrm{a}}$ & $1.74 \pm 0.3487^{\mathrm{a}}$ & $0.56 \pm 0.0222^{\mathrm{a}}$ & $86.79 \pm 0.3134^{\mathrm{a}}$ \\
BGN-SDF & $10.82 \pm 0.0839^{\mathrm{a}}$ & $4.90 \pm 0.0900^{\mathrm{b}}$ & $15.54 \pm 0.3029^{\mathrm{b}}$ & $0.54 \pm 0.0162^{\mathrm{a}}$ & $68.20 \pm 0.1811^{\mathrm{b}}$ \\
STASOL & $8.63 \pm 0.2500^{\mathrm{b}}$ & $4.88 \pm 0.0666^{\mathrm{b}}$ & $6.96 \pm 0.6749^{\mathrm{c}}$ & $0.84 \pm 0.0100^{\mathrm{b}}$ & $78.69 \pm 0.5500^{\mathrm{c}}$ \\
\hline
\end{tabular}

Values are mean \pm standard deviation. Means within a column followed by different superscripts are significantly $(p \leq 0.05)$ different; BGNS = Bambara groundnut starch; BGN-SDF = Bambara groundnut soluble dietary fibre STASOL = Bambara groundnut starch-soluble dietary fibre nanocomposite.

Lower protein values of $0.61 \%$ for BGNS have been reported by Sirivongpaisal [26], respectively, while comparable protein values in BGNS (1.77\%) were reported by Afolabi [20]. Generally, it was established that BGN starches have very low protein content indicating high purity. The yield of BGNS ranges from 22-46\% [27]. The varying amounts of BGNS among researchers can be attributed to different extraction methods, namely wet milling [19], dry milling [27] and alkaline extraction [26]. Despite the lower yield, dry milling was used in this study because of its water-energy efficiency compared to wet milling.

The yield of BGN-SDF was $15.2 \%$. The powder obtained was tasteless, odourless, fluffy and off-white. BGN-SDF was relatively high in proteins $(15.5 \%)$ and STASOL had a considerable amount of proteins (7.0\%) (Table 2).

STASOL was composed of BGNS and BGN-SDF at a ratio of 15:1.95 g/g, dry weight. The nanocomposite was a tasteless, odourless and fine white powder with $6.96 \%$ protein, $0.84 \%$ fat and $4.88 \%$ ash. Bambara groundnut starch and BGN-SDF did not differ significantly in their moisture $(p=0.620)$ and fat $(p=0.116)$ content, and both had a significantly $(p=0.000)$ higher moisture content and a significantly $(p=0.000)$ lower fat content than STASOL. Bambara groundnut SDF and STASOL were not significantly $(p=0.217)$ different in their ash content, and both had a significantly $(p=0.000)$ higher ash content than BGNS. Ash is an indication of the mineral content of samples and the high values obtained in BGN-SDF and STASOL suggested that they may contribute micro and macro elements to food systems [26].

\subsection{Particle Size and Conductivity of Bambara Groundnut Starch, Soluble Dietary Fibre and} Starch-Soluble Dietary Fibre Nanocomposite

The particle size of BGNS, BGN-SDF and STASOL was $23.79 \mu \mathrm{m}, 118.3 \mathrm{~nm}$ and $74.01 \mathrm{~nm}$, respectively. Particle size analysis gives information on the size and distribution 
of particles, therefore allowing for the prediction of their behaviour when exposed to certain conditions. A smaller particle size translates to an increased surface area to volume ratio thereby improving the dissolution and reaction rates. For composites to be considered nanocomposites, at least one dimension should be in the nano level $(<100 \mathrm{~nm})$ [28]. In this study, STASOL was the only biopolymer confirmed to be a nanocomposite. The mean particle size of BGNS $(23.79 \mu \mathrm{m})$ was within the 6-65 $\mu \mathrm{m}$ range reported by Kaptso [29] for various BGNS. It was also in the particle size range of chickpea starch $(6-31 \mu \mathrm{m})$, smooth pea $(14-37 \mu \mathrm{m})$ and cowpea $(3-64 \mu \mathrm{m})$

The zeta potential of BGNS, BGN-SDF and STASOL was $-2.03,-6.03$ and $-57.3 \mathrm{mV}$, respectively. The zeta potential of the three biopolymers was significantly $(p \leq 0.05)$ different. Zeta potential is the electric potential due to surface charge on a particle [30]. A negative zeta potential indicates the stability of a compound, with a higher negative value indicating higher stability. In this study, STASOL had the most negative zeta potential $(-57.3 \mathrm{mV})$ which was suggestive of high stability. BGNS and BGN-SDF were nano-sized but could not be considered nanocomposites because their sizes were above $100 \mathrm{~nm}$.

Gulu [7] produced a BGN starch-catechin complex using free radical-induced grafting (ascorbic acid $(0.1 \%)$ and hydrogen peroxide $(16.5 \%)$ and cyclodextrins as initiators. The researcher did not report on the particle size and conductivity of the complex but reported relatable functional and physicochemical results. The free radical-induced grafting of BGNS and BGN-SDF to form STASOL has never been studied before.

\subsection{Functional Groups of Bambara Groundnut Starch, Soluble Dietary Fibre and Starch-Soluble Dietary Fibre Nanocomposite}

Fourier transform infrared (FTIR) was carried out to assess the functional groups in BGNS, BGN-SDF and STASOL. All three biopolymers had a similar composition, which explained the resemblance in their IR spectra as shown in Figure 3.

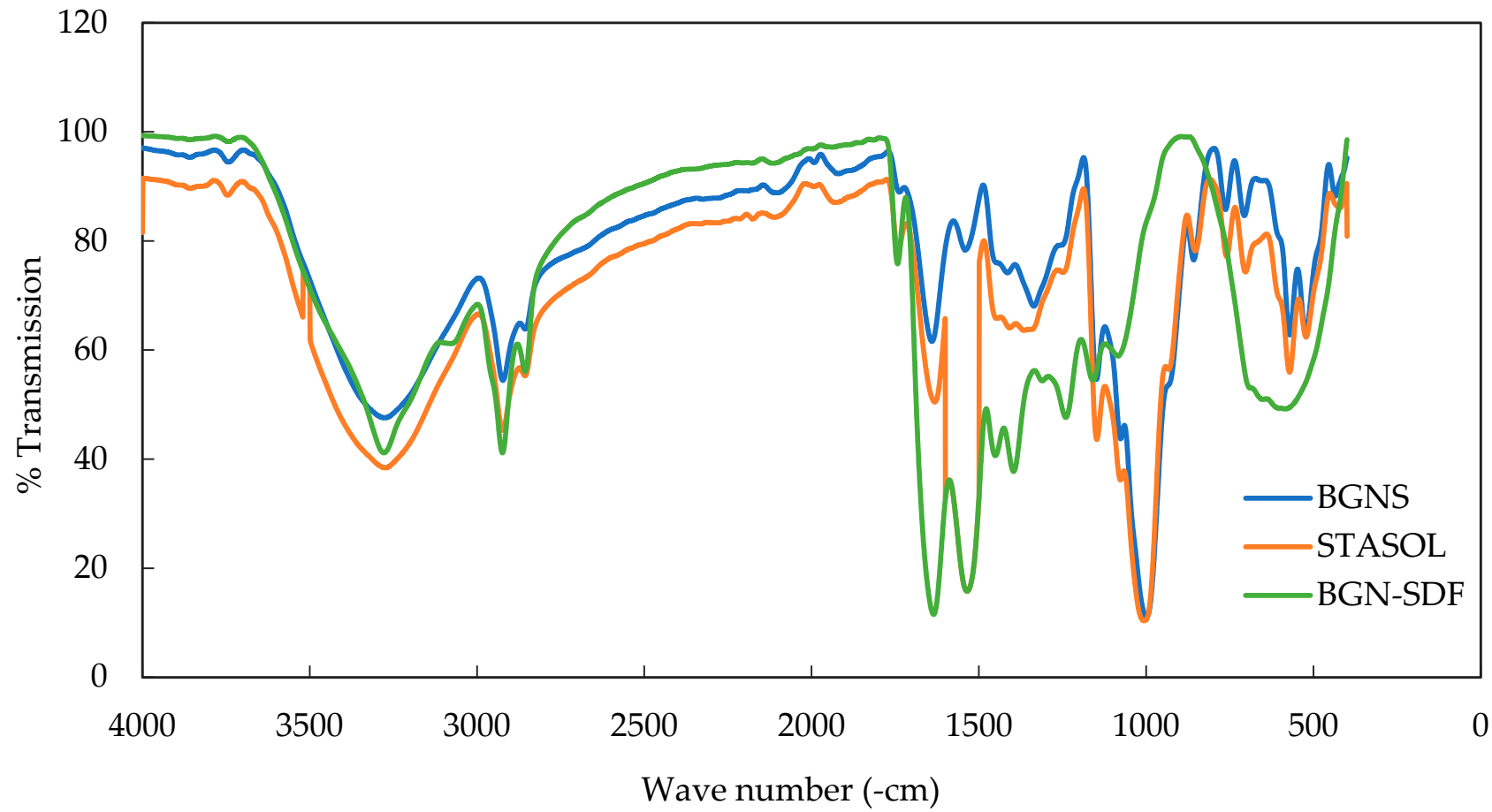

Figure 3. FTIR spectra of BGNS, BGN-SDF and STASOL. FTIR = Fourier transform infrared; BGNSBambara groundnut starch; BGN-SDF = Bambara groundnut soluble dietary fibre; STASOL = Bambara groundnut starch-fibre nanocomposite.

The IR spectra of BGNS showed a characteristic band with a peak at $2924.32 \mathrm{~cm}^{-1}$ in the region of $2800-3000 \mathrm{~cm}^{-1}$, that could be attributed to the stretching of C-H bonds. The presence of amylose and amylopectin, the building blocks of starch, influenced the 
absorbance of starch in this region [31]. Broadband in the region $3000-3600 \mathrm{~cm}^{-1}$ could be attributed to the vibrational stretching of the hydrogen-bonded $\mathrm{OH}$ groups [32]. These are associated with the inter- and intra-molecular bound $\mathrm{OH}$ groups having a polymeric association, which makes up the gross structure of starch [31]. The peaks in the region $1400-3380 \mathrm{~cm}^{-1}$ are characteristic of stretching vibrations and deformation of the $\mathrm{OH}$ bond of water while the peak at $1641.71 \mathrm{~cm}^{-1}$ is characteristic of $\mathrm{C}=\mathrm{O}$ of carboxyl groups as well as the vibration of $\mathrm{OH}$ of water molecules in the non-crystalline region of starch [31]. The absorbance in the region $900-1200 \mathrm{~cm}^{-1}$ was characteristic of polysaccharides and was indicative of the vibration of C-O, C-C and C-H-O bonds [7]. Absorbance at $400-861 \mathrm{~cm}^{-1}$ was indicative of the presence of sugars which was expected since starch is composed of long chains of glucose molecules. This further confirmed the presence of $\mathrm{C}, \mathrm{H}$ and $\mathrm{O}$ atoms which make up the skeleton of starch molecules. The bands between 800 and $1300 \mathrm{~cm}^{-1}$ represented the vibration of $\mathrm{C}-\mathrm{O}$ and $\mathrm{C}-\mathrm{C}$ bonds. Comparative peaks have been reported in the literature [32]. The peaks at $860.59,571.59$ and $522.93 \mathrm{~cm}^{-1}$ were only detected in BGNS.

The IR spectra for BGN-SDF had similar peaks to BGNS spectra at 3280.17, 2924.24 and $1633.68 \mathrm{~cm}^{-1}$ (Figure 3). The bands at 1633.68 and $1537.56 \mathrm{~cm}^{-1}$ could be attributed to the deformation of groups of primary amide $\mathrm{NH}$ suggesting the presence of protein [7]. The sharp peak at $2853.99 \mathrm{~cm}^{-1}$ was more pronounced in BGN-SDF than in BGNS. This could be because starch is only composed of glucose molecules while BGN-SDF has glucose, arabinose, galactose, fucose, fructose, mannose and xylose. The peaks at 1743.34, 1537.56, 1452.68 and $1237.96 \mathrm{~cm}^{-1}$ were present in BGN-SDF but absent in BGNS. The peak at $1237.96 \mathrm{~cm}^{-1}$ was representative of the $\mathrm{C}-\mathrm{O}$ stretch of $\mathrm{CH}_{2} \mathrm{OH}$. A pronounced peak at $1393.61 \mathrm{~cm}^{-1}$ was observed and was characteristic of $\mathrm{CH}_{3}$ vibration. This peak was absent in both BGNS and STASOL. The suggestive presence of amides and esters in BGN-SDF confirmed the complex nature of the dietary fibre.

The IR spectra of STASOL resembled those of BGNS and BGN-SDF (Figure 3). FTIR spectra of STASOL showed polysaccharide typical bands at $2923.77,3279.87$ and $1631.18 \mathrm{~cm}^{-1}$ [30]. The wavenumber $1077.11 \mathrm{~cm}^{-1}$ showed sharp peaks in BGNS $\left(1076.45 \mathrm{~cm}^{-1}\right)$ and BGNSDF $\left(1078.70 \mathrm{~cm}^{-1}\right)$ but was not sharp in STASOL, signifying a change in the structure of the new compound. BGNS and STASOL had peaks in the region $434.37-571.59 \mathrm{~cm}^{-1}$ while no peaks were detected in the BGN-SDF. The disappearance of these spectral bands in STASOL indicated that BGNS and BGN-SDF were successfully conjugated, resulting in the disruption of $\mathrm{C}-\mathrm{H}$ bonds as new bonds were formed. Of particular interest was the peak at $1531.55 \mathrm{~cm}^{-1}$ which was also observed on the IR spectrum of BGN-SDF $\left(1537.56 \mathrm{~cm}^{-1}\right)$ but was absent in BGNS.

The peak was due to the deformation of the $\mathrm{NH}$ of the primary amide group. The absence in BGNS could be suggestive of a low protein in the starch. A peak was observed at $996.68 \mathrm{~cm}^{-1}$ which corresponded with the peak in the BGNS spectrum $\left(995.22 \mathrm{~cm}^{-1}\right)$ but was absent in BGN-SDF. These observations indicated that STASOL possessed similar functional groups of both BGNS and BGN-SDF. A slight shift in peaks was observed in the STASOL (Figure 3) and this further suggested the successful formation of a new complex.

\subsection{Crystallinity of Bambara Groundnut Starch, Soluble Dietary Fibre and Starch-Soluble Dietary Fibre Nanocomposite}

The crystalline patterns of BGNS, BGN-SDF and STASOL are represented in Figure 4. 


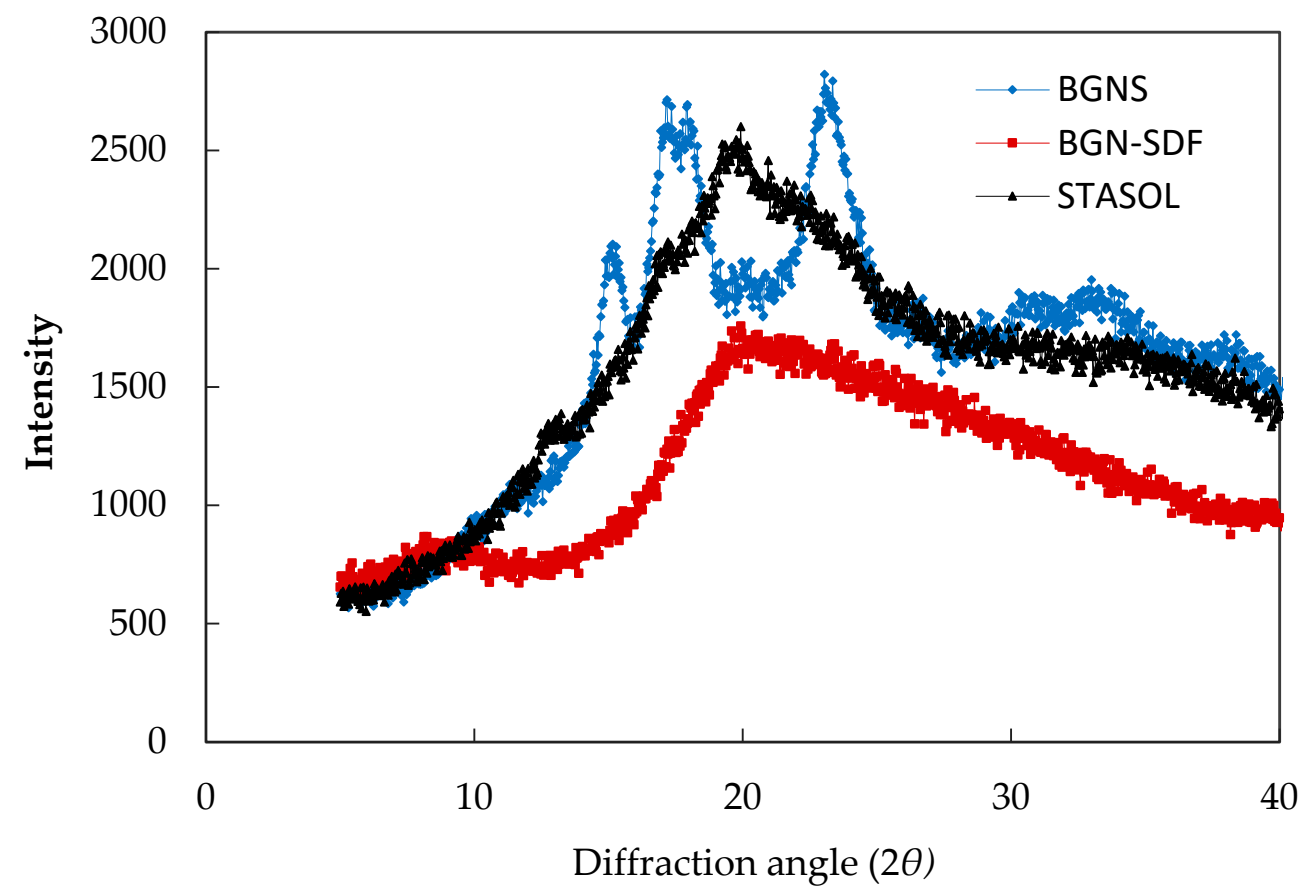

Figure 4. Powder X-ray diffraction patterns of BGNS, BGN-SDF and STASOL. BGNS = Bambara groundnut starch; BGN-SDF = Bambara groundnut soluble dietary fibre; STASOL = Bambara groundnut starch-fibre nanocomposite.

X-ray diffraction is used to reveal the characteristics of the crystalline structure of starch granules [24]. BGNS exhibited strong peaks at 15,17 and $23^{\circ}(2 \theta)$ which is typical of C-type diffraction pattern [33]. Type $\mathrm{C}$ crystallinity is typical in legumes and is therefore appropriate for BGNS. Type C consists of a mixture of type A and B polymorphs with peaks at 15,17 and $23^{\circ}$ [34]. Weaker peaks were observed at $10,12,20$ and $27^{\circ}$ and an extra peak was observed at $18^{\circ}$, thereby classifying BGNS as $C_{A}$-type starch. Type $C$ starch is classified as $\mathrm{C}_{\mathrm{A}}$-type (closer to A-type), $\mathrm{C}_{\mathrm{B}}$-type (closer to B-type) and $\mathrm{C}_{\mathrm{C}}$-type (typical C-type) according to the proportion of A- and B-type allomorphs. The XRD patterns of $\mathrm{C}_{\mathrm{A}}$ - and $\mathrm{C}_{\mathrm{B}}$-type starches are similar to those of $\mathrm{C}_{\mathrm{C}^{-}}$-type but exhibit a shoulder peak at about $18^{\circ} 2 \theta$ [35]. A strong singlet peak is exhibited at $23^{\circ} 2 \theta$ for $\mathrm{C}_{\mathrm{A}}$-type starch while two shoulder peaks at about $22^{\circ}$ and $24^{\circ} 2 \theta$ for $C_{B}$-type starch are common [35].

Type $C$ crystallinity has been reported for leguminous starch such as that from cowpea and BGN $[20,34]$. Several studies on BGN starches reported type $C$ patterns $[20,33]$. Type $C$ starch is characterised by lower digestibility compared to type A starches, typical of cereals. This in turn suggests a low glycemic index (GI) thereby making BGNS suitable for diabetics and desirable for weight conscious consumers [7].

BGN-SDF and STASOL did not exhibit any crystallinity as both compounds were amorphous in nature. Several researchers have reported the loss of crystallinity of legume starch following chemical treatment $[7,20]$. The loss of crystallinity makes starch amorphous thereby increasing the solubility of compounds in water [7]. This suggested that STASOL and BGN-SDF would be highly soluble in water while BGNS would be insoluble. As such, STASOL can find use as a thickener, stabiliser and in other food formulations that require dispersion in water.

3.6. Microstructure and Morphology of Bambara Groundnut Starch, Soluble Dietary Fibre and Starch-Soluble Dietary Fibre Nanocomposite

Scanning electron micrographs of BGNS, BGN-SDF and STASOL captured at a resolution of 20-200 $\mu \mathrm{m}$ are presented in Figure 5. 

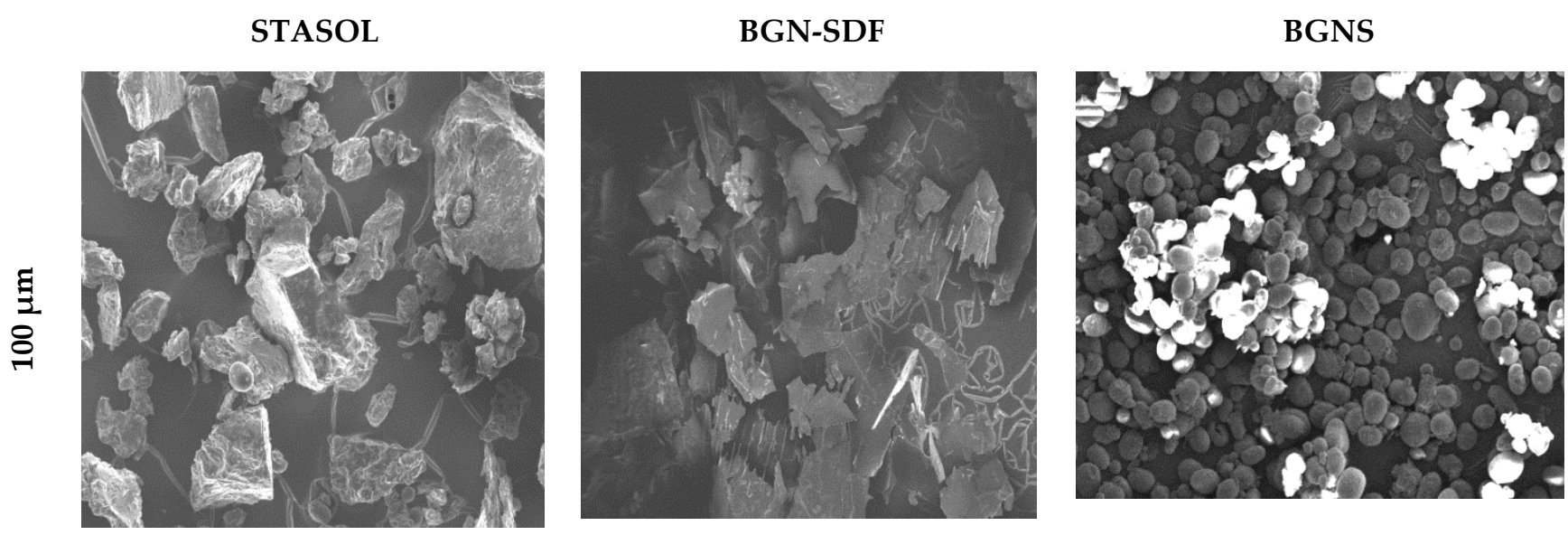

Figure 5. Microstructure of BGNS, BGN-SDF and STASOL. BGNS = Bambara groundnut starch; $\mathrm{BGN}-\mathrm{SDF}=$ Bambara groundnut soluble dietary fibre; STASOL = Bambara groundnut starch-soluble dietary fibre nanocomposite.

SEM gives the morphology and microstructure of materials and proves useful in studying the physicochemical properties of biopolymers [11]. BGNS granules exhibited a spherical structure with a smooth, unfractured surface typical of BGN starches, suggesting a significant purity of the extracted particles [7,32]. BGN-SDF and STASOL exhibited irregular and polygonal forms. These results were in fair agreement with the research of Diedericks and Jideani [2] and Maphosa and Jideani [12] and they corresponded with XRD patterns observed in Figure 4. The microstructure of STASOL suggested the successful formation of a new compound from BGNS and BGN-SDF.

3.7. Fluorescence Spectra of Bambara Groundnut Starch, Soluble Dietary Fibre and Starch-Soluble Dietary Fibre Nanocomposite

The fluorescence spectra of BGNS, BGN-SDF and STASOL are shown in Figure 6. BGNS had an emission spectrum at $255 \mathrm{~nm}$ while BGN-SDF and STASOL had emission spectra at $350 \mathrm{~nm}$.

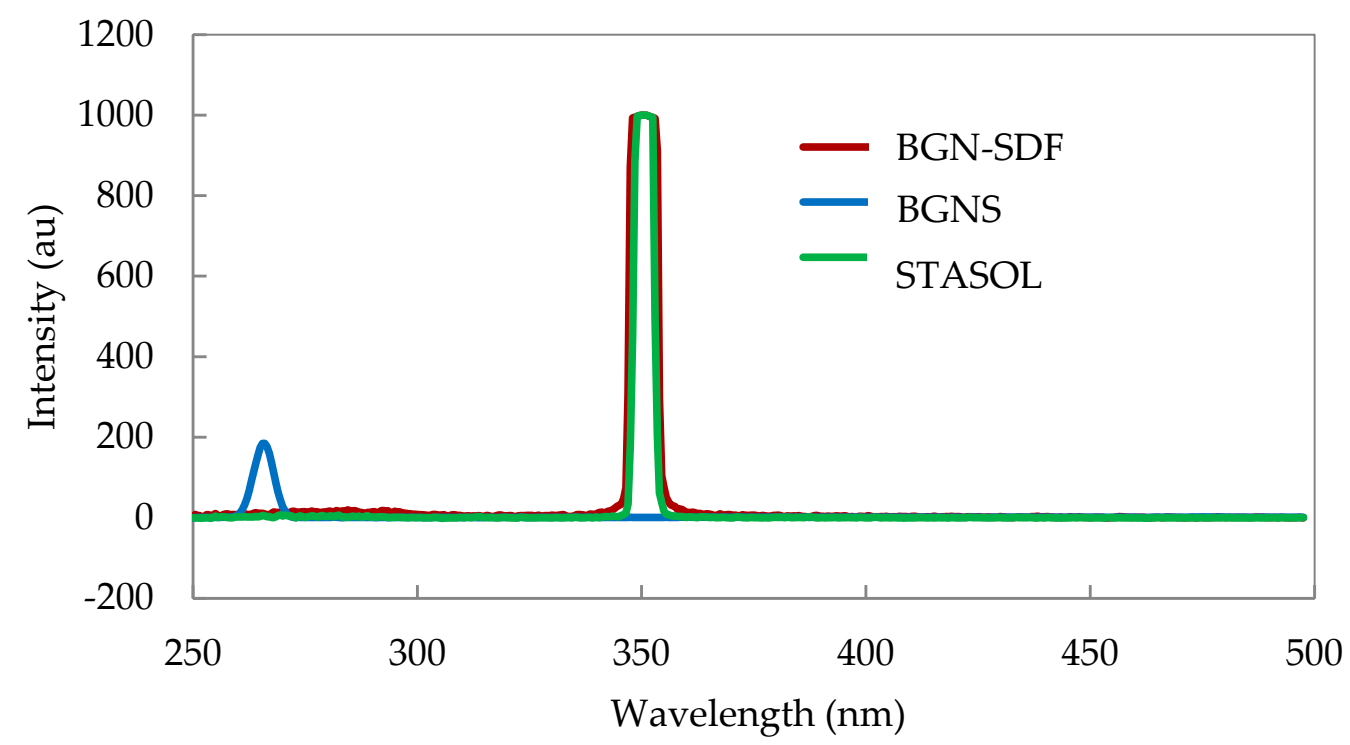

Figure 6. Fluorescence spectra of BGNS, BGN-SDF and STASOL. BGNS = Bambara groundnut starch; BGN-SDF = Bambara groundnut soluble dietary fibre; STASOL = Bambara groundnut starchfibre nanocomposite. 
Fluorescence spectroscopy involves the excitation (absorption) and emission (fluorescence) of wavelengths and the subsequent collection of two spectra. It is used as a non-destructive analytical technique to provide information on the presence of fluorescent molecules and reveals the conformational changes in modified starches [36]. In this study, fluorescence spectroscopy was used as one of the methods to verify the formation of STASOL from its parent compounds, BGNS and BGN-SDF. STASOL was produced from $88.5 \%$ BGNS and $11.5 \%$ BGN-SDF. It was therefore assumed that if any of the parent compounds had an effect on its fluorescence properties, it would be BGNS.

The excitation emission matrices spectra were recorded from 250 to $500 \mathrm{~nm}$ at $5 \mathrm{~nm}$ intervals. The emission wavelength of STASOL (350 nm) was the same as that of BGN-SDF.

The chemical grafting of BGN-SDF involved the modification of BGNS using ascorbic acid and $\mathrm{H}_{2} \mathrm{O}_{2}$ redox pair [7]. The process caused a change in the intra- and inter-molecular bonds of BGNS, and this could explain the difference between the emission wavelength of the major primary raw material, BGNS (255 nm) and STASOL (350 nm). This difference suggested the formation of new functional groups in STASOL as seen in the FTIR spectra (Figure 3). However, this was inconclusive, and more verification tests were carried out, namely, thermal characterisation, FTIR and powder XRD.

\subsection{Thermal Properties of Bambara Groundnut Starch, Soluble Dietary Fibre and Starch-Soluble Dietary Fibre Nanocomposite}

The study of the thermal behaviour of materials is important in establishing a relationship between temperature and specific physical properties. The data collected give insight into the behaviour of a particular material when exposed to elevated temperatures [32]. The thermal properties of BGNS, BGN-SDF and STASOL were determined using DSC and the thermograms are illustrated in Figure 7.

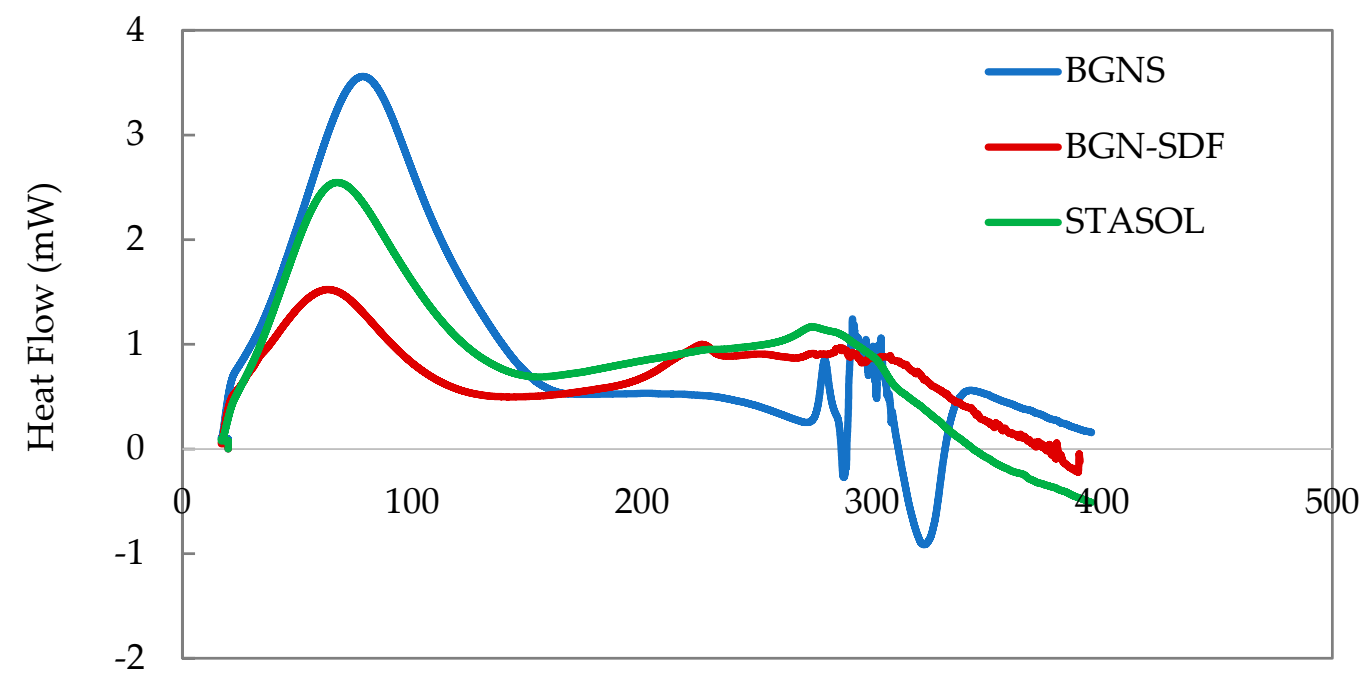

Temperature $\left({ }^{\circ} \mathrm{C}\right)$

Figure 7. Thermal properties of BGNS, BGN-SDF and STASOL using differential scanning colorimetry (DSC). BGNS = Bambara groundnut starch; BGN-SDF = Bambara groundnut soluble dietary fibre; $\mathrm{STASOL}=$ Bambara groundnut starch-fibre nanocomposite.

A major peak was observed for BGNS, BGN-SDF and STASOL at 77.19, 68.84 and $65.50{ }^{\circ} \mathrm{C}$ with areas of $1420.91,397.79$ and $875.01 \mathrm{~mJ}$, respectively (Table 3). 
Table 3. Thermal properties of BGNS, BGN-SDF and STASOL using differential scanning calorimetry.

\begin{tabular}{ccccccc}
\hline & \multicolumn{3}{c}{ Peak 1 } & \multicolumn{2}{c}{ Peak 2 } \\
\hline & ${\text { Peak }\left({ }^{\circ} \mathbf{C}\right)}$ & Area $(\mathbf{m J})$ & $\boldsymbol{\Delta H}(\mathbf{J} / \mathbf{g})$ & ${\text { Peak }\left({ }^{\circ} \mathbf{C}\right)}^{\text {Area }}(\mathbf{m J})$ & $\Delta \mathbf{H}(\mathbf{J} / \mathbf{g})$ \\
\hline BGNS & $77.19 \pm 0.4^{\mathrm{a}}$ & $1420.91 \pm 49^{\mathrm{a}}$ & $458.36 \pm 16^{\mathrm{a}}$ & $279.52 \pm 0.3^{\mathrm{a}}$ & $18.10 \pm 6^{\mathrm{a}}$ & $5.84 \pm 1.9^{\mathrm{a}}$ \\
BGN-SDF & $68.84 \pm 2.3^{\mathrm{ab}}$ & $397.79 \pm 127^{\mathrm{b}}$ & $297.54 \pm 110^{\mathrm{b}}$ & $230.30 \pm 0.2^{\mathrm{a}}$ & $18.70 \pm 2^{\mathrm{a}}$ & $13.9 \pm 1.8^{\mathrm{ab}}$ \\
STASOL & $65.50 \pm 1.4^{\mathrm{b}}$ & $875.01 \pm 33^{\mathrm{b}}$ & $261.36 \pm 15^{\mathrm{b}}$ & $293.14 \pm 12^{\mathrm{a}}$ & $83.98 \pm 6^{\mathrm{b}}$ & $25.09 \pm 2.3^{\mathrm{b}}$ \\
\hline
\end{tabular}

Values are mean \pm standard deviation. Means within a column followed by different superscripts are significantly $(p \leq 0.05)$ different. BGNS = Bambara groundnut starch; BGN-SDF = Bambara groundnut soluble dietary fibre; STASOL = Bambara groundnut starch-soluble dietary fibre nanocomposite.

The initial thermal transition of the three biopolymers ranged from 65.50 to $77.19^{\circ} \mathrm{C}$ and could be attributed to the loss of moisture and volatile compounds, which is a typical endothermic process [30]. The first peak of BGNS at $77.19^{\circ} \mathrm{C}$ represents the gelatinisation of starch [10]. Maphosa [11] also reported minor undulations in the thermographs of BGNSDFs at temperatures below $100{ }^{\circ} \mathrm{C}$ and attributed it to the loss of moisture which could have been absorbed by the hygroscopic powders. Higher results of the peak degradation of starch due to gelatinisation were reported for BGNS $\left(81.66^{\circ} \mathrm{C}\right)$ and BGN flour $\left(81^{\circ} \mathrm{C}\right)$ [32]. Lower gelatinisation temperatures of BGNS were reported as $75.33^{\circ} \mathrm{C}$ [26] and $76.4^{\circ} \mathrm{C}$ [33]. The changes in enthalpy $(\Delta \mathrm{H})$ of the first peaks of the biopolymers corresponded with the moisture contents of the biopolymers. As observed, less energy was required in dispelling moisture from STASOL, thus it can be assumed that it had the minimum moisture content. The maximum degradation of the biopolymers occurred at $279.52,230.30$ and $293.14{ }^{\circ} \mathrm{C}$ for BGNS, BGN-SDF and STASOL, respectively (Figure 7). STASOL had the highest enthalpy change of reaction $(25.09 \mathrm{~J} / \mathrm{g})$ while BGNS had the lowest $(5.84 \mathrm{~J} / \mathrm{g})$. This indicated that STASOL had relatively higher thermal stability which was suggestive of the introduction of strong intra- and inter-molecular bonds during the production of the nanocomposite. BGNS required the least amount of energy for the disintegration of bonds because it is comparatively simpler in structure. BGN-SDF, on the other hand, is composed of chemically complex polysaccharides. STASOL was produced from the conjugation of BGNS and BGNSDF, introducing new functional groups during the chemical grafting process. This was in agreement with the FTIR results (Figure 3). The degradation of STASOL peaked at $239^{\circ} \mathrm{C}$. This alluded to its stability to withstand high thermal processing such as baking which has temperatures varying between $176{ }^{\circ} \mathrm{C}$ and $250{ }^{\circ} \mathrm{C}$ [37]. A pronounced peak at $322.86{ }^{\circ} \mathrm{C}$ was observed on the BGNS thermogram, representing the final decomposition of starches. The exothermic behaviour showed that BGNS was charred instead of volatilised at the final degradation stage, meaning the molecules released energy as they combusted [38]. This was confirmed by examining the DSC pans post-analysis, revealing charred samples.

Thermogravimetric analysis (TGA) measures the loss of mass in a sample as a function of temperature. The thermal properties of BGNS, BGN-SDF and STASOL determined using TGA are illustrated in Figure 8.

The initial weight loss and weight loss temperature for BGNS, BGN-SDF and STASOL were $11.84 \%$ at $319.82{ }^{\circ} \mathrm{C}, 11.30 \%$ at $295.37^{\circ} \mathrm{C}$ and $11.25 \%$ at $311.66^{\circ} \mathrm{C}$, respectively. At temperatures below $100{ }^{\circ} \mathrm{C}$, weight loss occurred due to the evaporation of water and loss of volatile matter compounds. This was in agreement with the mass lost due to evaporation observed in DSC studies (Figure 7). This corresponded with the particle sizes of the biopolymers where STASOL and BGNS had the smallest and highest average particle sizes, respectively. Therefore, STASOL had the largest surface area to volume ratio, hence more heat was absorbed by the water molecules leading to increased kinetic energy and subsequently translated to a faster rate of evaporation. There was no significant difference in the final weight of BGN-SDF and STASOL while both differed significantly $(p=0.000)$ from the final weight of BGNS. The final weight loss temperature of BGNS and BGN-SDF as well as BGN-SDF and STASOL differed significantly $(p=0.000)$. The remaining mass at the end of TG analysis was concluded to be ash [38]. The amount of ash remaining was STASOL > BGN-SDF > BGNS. The moisture content of BGNS (10.84\%), BGN-SDF (10.82\%) 
and STASOL (8.63\%) (Table 2) was in fair agreement with differential scanning calorimetry studies (Table 3) where less energy was required in dispelling moisture from STASOL as it had the minimum reported moisture content. These results were further confirmed by TGA (Figure 8) where the highest and lowest mass loss due to moisture was observed in BGNS and STASOL, respectively.

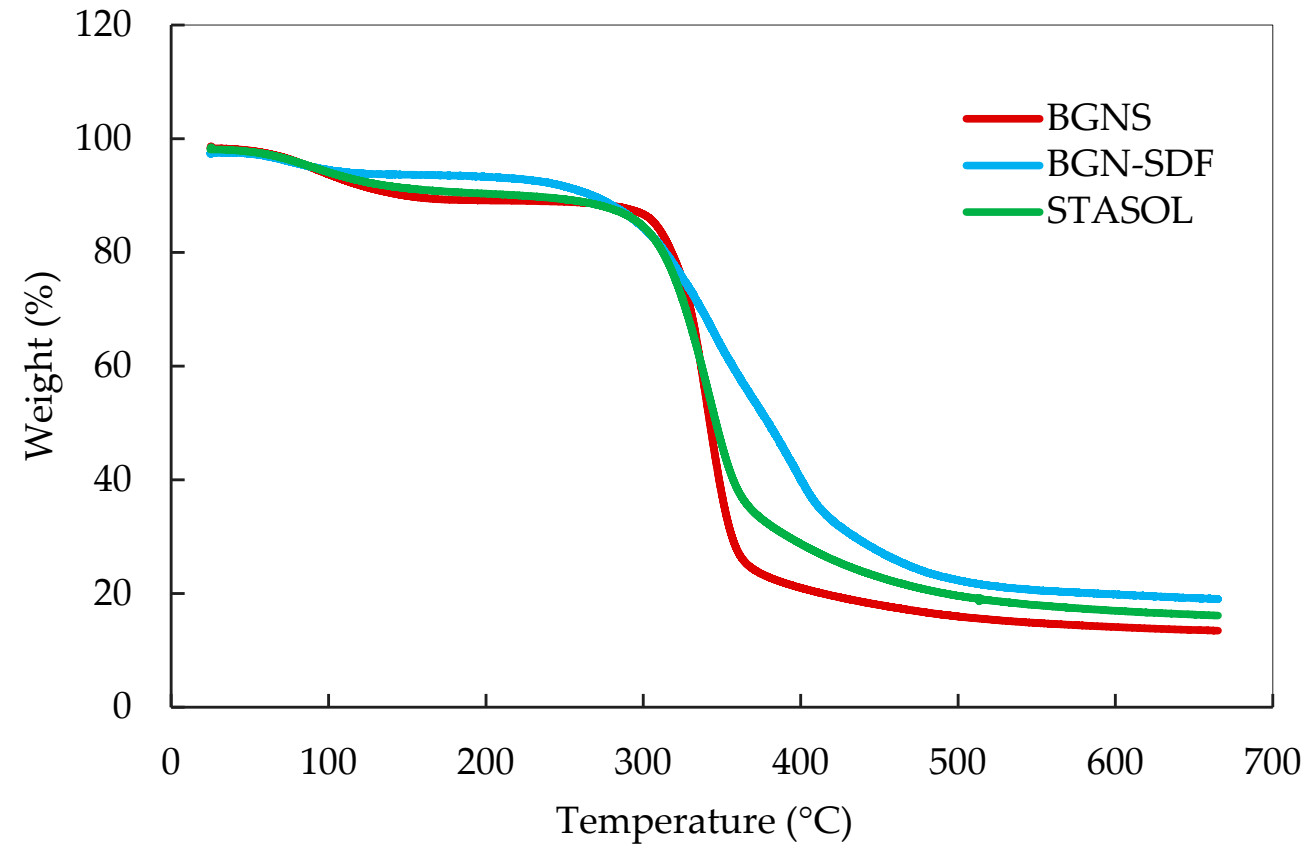

Figure 8. Thermal properties of BGNS, BGN-SDF and STASOL using TGA. BGNS = Bambara groundnut starch; BGN-SDF = Bambara groundnut soluble dietary fibre; STASOL = Bambara groundnut starch-fibre nanocomposite; TGA = thermogravimetric analysis.

\section{Conclusions}

Starch modification by grafting onto BGN-SDF significantly improved the thermal behaviour of native BGNS. STASOL was successfully synthesised from BGNS and BGN-SDF using an ascorbic acid-hydrogen peroxide redox system. The particle size and conductivity of STASOL proved its high stability and confirmed its nano nature. The disappearance and emergence of FTIR spectral bands in STASOL indicated the disruption and formation of new bonds, confirming the successful formation of a new compound from BGNS and BGN-SDF. The degradation of STASOL indicated desirable thermal resistance, suggesting usefulness in high temperature food applications such as extrusion and baking.

Author Contributions: Conceptualisation, V.A.J.; methodology, V.A.J. and Y.M.; formal analysis, V.A.J.; investigation, Y.M.; resources, V.A.J.; writing original draft preparation, Y.M.; review and editing, Y.M., D.I.I.-O. and V.A.J.; supervision, V.A.J. and D.I.I.-O.; funding acquisition, V.A.J. and Y.M. All authors have read and agreed to the published version of the manuscript.

Funding: This work was funded by the Cape Peninsula University of Technology (CPUT) Research Fund and CPUT Vice Chancellor's prestigious award.

Institutional Review Board Statement: Not applicable.

Informed Consent Statement: Not applicable.

Data Availability Statement: Not applicable.

Conflicts of Interest: The authors declare no conflict of interest. 


\section{References}

1. Jideani, V.A.; Mpotokwana, S.M. Modelling of water absorption of Botswana Bambara varieties using Peleg's equation. J. Food Eng. 2009, 92, 182-188. [CrossRef]

2. Diedericks, C.F.; Jideani, V.A. Nutritional, Therapeutic and Prophylactic Properties of Vigna subterranea and Moringa Oleifera. J. Food Sci. Technol. 2014, 52, 4078-4089. [CrossRef]

3. Murevanhema, Y.Y.; Jideani, V.A. Potential of Bambara groundnut (Vigna subterranea (L.) Verdc) milk as a probiotic beverage: A review. Crit. Rev. Food Sci. Nutr. 2013, 53, 954-967. [CrossRef] [PubMed]

4. Ye, A. Complexation between milk proteins and polysaccharides via electrostatic interaction: Principles and applications: A review. Int. J. Food Sci. Technol. 2008, 43, 406-415. [CrossRef]

5. Oyeyinka, S.A.; Singh, S.; Ma, Y.; Amonsou, E.O. Effect of high-pressure homogenization on structural, thermal and rheological properties of Bambara starch complexed with different fatty acids. R. Soc. Chem. 2016, 6, 80174-80180. [CrossRef]

6. Gammans, M.; Merel, P.; Ortiz-Bobea, A. Negative impacts of climate change on cereal yields: Statistical evidence from France. Environ. Res. Lett. 2017, 12, 054007. [CrossRef]

7. Gulu, N.B. Functional and Rheological Properties of Bambara Groundnut Starch-Catechin Complex Obtained by Chemical Grafting. Master's Thesis, Cape Peninsula University of Technology, Cape Town, South Africa, 2018. Available online: http: / / etd.cput.ac.za/handle/20.500.11838/2806 (accessed on 20 November 2021).

8. Winarti, C.; Sunarti, T.; Mangunwidjaja, D.; Richana, N. Preparation of arrowroot starch nanoparticles by butanol-complex precipitation, and as bioactive encapsulation matrix. Int. Food Res. J. 2014, 21, 2207-2213.

9. Wang, S.; Wang, J.; Zhang, W.; Li, C.; Yu, J.; Wang, S. Molecular order and functional properties of starches from three waxy wheat varieties grown in China. Food Chem. 2015, 181, 43-50. [CrossRef]

10. Ashogbon, A.O.; Akintayo, E.T. Morphological and functional properties of starches from cereal and legume: A comparative study. Int. J. Biotechnol. Food Sci. 2013, 1, 72-83.

11. Maphosa, Y. Characterisation of Bambara Groundnut (Vigna Subterranea (L) Verdc.) Non-Starch Polysaccharides from Wet Milling as Prebiotics. Master's Thesis, Cape Peninsula University of Technology, Cape Town, South Africa, 2016. Available online: http:/ / etd.cput.ac.za/handle/20.500.11838/2342 (accessed on 20 November 2021).

12. Maphosa, Y.; Jideani, V.A. Physicochemical characteristics of Bambara groundnut dietary fibres extracted using wet milling. $S$. Afr. J. Sci. 2016, 112, 1-8. [CrossRef]

13. Spizzirri, U.G.; Altimari, I.; Puoci, F.; Parisi, O.I.; Iemma, F.; Picci, N. Innovative antioxidant thermo-responsive hydrogels by radical grafting of catechin on inulin chain. Carbohydr. Polym. 2011, 84, 517-523. [CrossRef]

14. Liu, Y.; Chen, W.; Chen, C.; Zhang, J. Physicochemical Property of Starch-Soluble Dietary Fiber Conjugates and Their Resistance to Enzymatic Hydrolysis. Int. J. Food Prop. 2015, 18, 2457-2471. [CrossRef]

15. Singh, S.; D'Sa, E.; Swenson, E. Seasonal variability in CDOM absorption and fluorescence properties in the Barataria Basin, Louisiana, USA. J. Environ. Sci. 2010, 22, 1481-1490. [CrossRef]

16. Fama, L.; Gerschenson, L.; Goyanes, S. Starch-vegetable fibre composites to protect food products. Carbohydr. Polym. 2009, 75, 230-235. [CrossRef]

17. Spizzirri, U.G.; Parisi, O.I.; Iemma, F.; Cirillo, G.; Puoci, F.; Curcio, M.; Picci, N. Antioxidant-polysaccharide conjugates for food application by eco-friendly grafting. Carbohydr. Polym. 2010, 79, 333-340. [CrossRef]

18. Adeyi, O.; Ikhu-Omoregbe, D.; Jideani, V. Emulsion stability and steady shear characteristics of concentrated oil-in-water emulsion stabilized by gelatinized bambara groundnut flour. Asian J. Chem. 2014, 26, 4995-5002. [CrossRef]

19. Ramirez-Sanchez, I.; Maya, L.; Ceballos, G.; Villarreal, F. Fluorescent detection of (-)-epicatechin in microsamples from cacao seeds and cocoa products: Comparison with Folin-Ciocalteu method. J. Food Compos. Anal. 2010, 23, 790-793. [CrossRef]

20. Afolabi, T.A. Synthesis and physicochemical properties of carboxymethylated bambara groundnut (Voandzeia subterranea) starch. Int. J. Food Sci. Technol. 2012, 47, 445-451. [CrossRef]

21. Rosell, C.M.; Santos, E.; Collar, C. Physico-chemical properties of commercial fibres from different sources: A comparative approach. Food Res. Int. 2009, 42, 176-184. [CrossRef]

22. Adeyi, O. Effect of Bambara Groundnut Flour on the Stability and Rheological Properties of Oil-In-Water Emulsion. Ph.D. Thesis, Cape Peninsula University of Technology, Cape Town, South Africa, 2014. Available online: http://hdl.handle.net/11189/1889 (accessed on 18 November 2021).

23. Maphosa, Y.; Jideani, V.A. The Role of Legumes in Human Nutrition. In Functional Food-Improve Health through Adequate Food; Hueda, M.C., Ed.; InTech: London, UK, 2017. [CrossRef]

24. Jha, P.K.; Desai, P.S.; Li, J.; Larson, R.G. pH and salt effects on the associative phase separation of oppositely charged polyelectrolytes. Polymer 2014, 6, 1414-1436. [CrossRef]

25. Tolstoguzov, V. Food Polysaccharides and Their Applications. In Food Science and Technology, 2nd ed.; Alistair, M., Stephen, G.O., Phillips, P., Williams, A., Eds.; CRC Press, Taylor \& Francis: New York, NY, USA, 2006; p. 589.

26. Sirivongpaisal, P. Structure and functional properties of starch and flour from bambarra groundnut. Songklanakarin J. Sci. Technol. 2008, 30, 51-56. [CrossRef]

27. Adebowale, K.O.; Afolabi, T.; Lawal, O.S. Isolation, chemical modification and physicochemical characterisation of Bambarra groundnut (Voandzeia subterranea) starch and flour. Food Chem. 2002, 78, 305-311. [CrossRef] 
28. Rauscher, H.; Rasmussen, K.; Sokull-Klüttgen, B. Regulatory Aspects of Nanomaterials in the EU. Chem. Ing. Tech. 2017, 89, 224-231. [CrossRef]

29. Kaptso, K.G.; Njintang, Y.N.; Nguemtchouin, M.M.G.; Scher, J.; Hounhouigan, J.; Mbofung, C.M. Physicochemical and microstructural properties of flours, starch and proteins from two varieties of legumes: Bambara groundnut (Vigna subterranea). J. Food Sci. Technol. 2015, 52, 4915-4924. [CrossRef] [PubMed]

30. Ferraris, S.; Cazzola, M.; Peretti, V.; Stella, B.; Spriano, S. Zeta Potential Measurements on Solid Surfaces for in vitro Biomaterials Testing: Surface Charge, Reactivity upon Contact with Fluids and Protein Absorption. Front. Bioeng. Biotechnol. 2018, 6, 60. [CrossRef] [PubMed]

31. Oyeyinka, S.A.; Singha, S.; Adebola, P.; Amonsou, E. Physicochemical properties of starches with variable amylose contents extracted from bambara groundnut genotypes. Carbohydr. Polym. 2015, 133, 171-178. [CrossRef] [PubMed]

32. Zhang, J.; Wang, Z.W. Soluble dietary fibre from Canna edulis Ker by-product and its physicochemical properties. Carbohydr. Polym. 2013, 92, 289-296. [CrossRef]

33. Oyeyinka, S.A.; Oyeyinka, A.T. A review on isolation, composition, physicochemical properties and modification of Bambara groundnut starch. Food Hydrocolloid 2017, 75, 62-71. [CrossRef]

34. Sandhu, K.S.; Lim, S.T. Digestibility of legume starches as influenced by their physical and structural properties. Carbohydr. Polym. 2008, 71, 245-252. [CrossRef]

35. Parri, E.; Santinami, G.; Domenici, V. Front-Face Fluorescence of Honey of Different Botanic Origin: A Case Study from Tuscany (Italy). Appl. Sci. 2020, 10, 1776. [CrossRef]

36. Skoog, A.; Wedborg, M.; Fogelqvist, E. Photobleaching of fluorescence and the organic carbon concentration in a coastal environment. Mar. Chem. 1996, 55, 333-345. [CrossRef]

37. Therdthai, N.; Zhou, W.; Adamczak, T. Optimisation of the temperature profile in bread baking. J. Food Eng. 2002, 55, 41-48. [CrossRef]

38. Wahyuningtiyas, N.E.; Suryanto, H. Analysis of Biodegradation of Bioplastics Made of Cassava Starch. J. Mech. Eng. Sci. Technol. 2017, 1, 41-54. [CrossRef] 